\title{
A New Model for Location and Transportation Problem of Cross-Docks in Distribution Networks
}

\author{
A. Hasani Goodarzi and S. H. Zegordi
}

\begin{abstract}
This paper considers a location and transportation problem in a distribution network with a set of part suppliers, cross-docking centers and assembly plants known as customers. In usual studies investigating crossdocking networks, all vehicles are forced to pass through crossdocks even if they pick up and deliver the same set of goods and products. In order to eliminate unnecessary stops at crossdocking centers and reduce transportation costs, we address a distribution network in which shipments are allowed to be transferred from suppliers to assembly plants directly as well as through cross-docks (indirect shipment). A mathematical model is developed for this problem in which the best location for establishing cross-docks is determined while simultaneously suppliers and plants are allocated to cross-docking centers in order to transport parts via two transportation strategies: direct shipment and shipment through cross-docks. In order to solve the model GAMS software has been used and some numerical examples are performed, in small and medium size problem instances. The results are reported in terms of total cost of the network and computational time.
\end{abstract}

Index Terms-Cross-docking, direct shipment, distribution network, location problem, mathematical model.

\section{INTRODUCTION}

Nowadays many supply chains and companies are trying to improve their distribution strategies to effectively move products in the network, since about $30 \%$ of a product price is incurred in the distribution process [1]. There are several strategies in distribution networks including direct shipping, milk runs, cross-docking and tailored networks [2]. Crossdocking is known as a logistic technique implemented to consolidate shipments from various sources and sort them for distribution and deliver to different final destinations. After collecting products from various origins (suppliers), inbound vehicles carry shipments to the cross-docks (CDs). Then they are unloaded at the inbound doors, sorted, consolidated according to destination of products and reloaded into outgoing vehicles at the outbound doors within less than 36 hours. Other handling operations including weighing, sizing, packaging, pricing and product labeling can be done on shipments.

Shipping small orders by individual vehicles results in "Less than Truck-Load" (LTL) shipments in which the entire vehicle capacity is not occupied, while in crossdocking strategy, small orders are consolidated into one big shipment to use the whole vehicle capacity (Full-TruckLoad). Therefore this approach reduces the numbers of

Manuscript received September 23, 2017; revised December 12, 2017.

A. Hasani Goodarzi and S. H. Zegordi are with the Industrial Engineering in the Faculty of Industrial \& Systems Engineering at Tarbiat Modares University, Tehran, Iran (e-mail: asefeh.hasani@modares.ac.ir, Zegordi@modares.ac.ir) utilized vehicles and helps to make more frequent and economical pickup and deliveries by trying to meet the entire vehicle capacity [3].

Apart from reducing transportation cost and consolidation of shipments, some other important advantages of crossdocking are reducing inventory level and need for warehouse space, decreasing labor cost, improving service level, and balancing demand and supply.

Cross-docking approach cannot be implemented in any condition. Some goods and products are more suited to implement this approach, including fast-moving products with constant demand [4] or low demand variance, perishable items needing immediate shipment, high quality products that do not require quality inspections during receiving process, products that are pre-tagged and ready for sale at the customer.

In the literature on cross-docking, problems are defined in strategic and operational level. The problems in strategic level are often related to decisions that are not made frequently, for instance the location of cross-docks and their layout. In the operational level, decisions are made for short term (daily, weekly or monthly) including decisions about dock door assignment, vehicle routing and scheduling problems. Recently cross-docking approach has attracted strong attention among researchers especially in the field of vehicle routing scheduling problem.

The work of Lee et al. [5] was seemingly the first study that investigated vehicle routing scheduling in cross-docking problem (VRPCD). They considered a cross-dock in order to transport goods from a set of suppliers to retailers. The authors proposed a Tabu search (TS) method to determine the number of vehicles and the optimal vehicle routing schedule at cross-dock. Then, Liao et al. [6] presented a TS algorithm to solve the model proposed by Lee et al. [5] and compared the results with those of Lee et al. [5]. Vahdani et al. [7] also considered the model of [5] and suggested a hybrid metaheuristic algorithm to solve it. The algorithm combines particle swarm optimization (PSO), variable neighborhood search (VNS) and simulated annealing (SA) in a population-based context. Numerical results indicated that the hybrid metaheuristic algorithm outperforms the TS proposed by [5].

Musa et al. [8] addressed the transportation problem in cross-docking networks and assumed that the shipments could be transferred from suppliers to customers directly, as well as via cross-docks. They presented an Ant Colony Optimization (ACO) algorithm to solve the proposed model. Dondo et al. [9] considered the vehicle routing and scheduling problem in a multi-echelon multi-item crossdocking network with time windows and presented a mixedinteger linear programming (MILP) formulation for it. The objective function tries to meet the customer demands at 
minimum total transportation cost. Ma et al. [10] investigated a consolidation and transportation problem in cross-docking distribution networks to find the trade-offs between transportation cost, inventory and scheduling requirements.

Santos et al. [11] extended the usual VRP in crossdocking (VRPCD) in a way that a cost will be added in the objective function whenever a good is moved from a vehicle to another one at the cross-docking center. Then, Santos et al. [12] extended their previous study by considering a VRPCD in which vehicles are permitted to avoid the stop at the cross-dock after pickup process. They presented an integer programming (IP) model for problem and applied a Branchand-price method to solve it.

Konur and Golias [13] formulated a bi-objective bi-level optimization problem to determine a cost-stable scheduling at inbound doors of cross-dock that minimizes the average of total service costs. They utilized a genetic algorithm (GA) to find an efficient Pareto frontier. Tarantilis [14] addressed a multi-source vehicle routing problem with a single crossdocking center and employed a TS algorithm in order to solve it. Mousavi and Tavakkoli-Moghaddam [15] and Mousavi et al. [16] addressed strategic, tactical and operational decision levels by considering the location problem of multiple cross-docking facilities and vehicle routing scheduling problem. In Mousavi and TavakkoliMoghaddam [15], the problem has been made more realistic by considering uncertainty in decision levels. They developed a two-phase mixed-integer linear programming (MILP) formulation and incorporated two types of uncertainties into mathematical formulation by proposing a hybrid fuzzy possibilistic-stochastic approach.

Hasani Goodarzi and Zegordi [17] also investigated a location-routing problem (LRP) in a deterministic distribution network as an integrated model. They developed a mixed integer non-linear programing (MINLP) formulation for the problem in which the best location of cross-docks is determined and simultaneously a fleet of vehicles is utilized to transport products from part suppliers to customers. As considered in the current study, two transportation strategies include direct shipment and indirect shipment (through cross-dock).

In order to study more in this scope, the reader can find more information on [18]-[20].

Going through the literature shows that the locationallocation problem in cross-docking requires some adoptions in order to be applicable in real world environments. In some cases, the picked up shipment from a typical supplier may be near FTL or geographical distribution of nodes is in a way that passing through cross-docks is not cost effective. Therefore, in distribution networks with cross-docks, moving shipments through cross-dock and consolidation process should be done when it is rationale. Using these considerations, this study tries to present a new formulation.

\section{PROBLEM DEFINITION}

\section{A. Assumptions}

The distribution network in this study includes suppliers, cross-docks, and assembly plants (as customers). The transportation system for shipping loads to plants includes direct and indirect shipments (via cross-docks). By using cross-docking strategy, products in various locations are collected in the cross-dock prior to transportation to their final destination. The loads sent to the cross-dock are consolidated according to their final destination. The demand of a typical assembly plant served by direct shipment strategy usually is near FTL.

The model tries to find the best location of cross-dock(s) and distribution plan such that the total transportation cost is minimized. Therefore, the programming model determines the shipments to be sent directly from suppliers to plants and loads to be sent indirectly through cross-docking centers, also the optimal location of cross-docks.

A plant may demand several products provided by several suppliers. All plants are directly connected to one or more cross-docks. It is not possible to have routes between nodes in the pick up or delivery process. Fig. 1 shows the flow of products in the proposed cross-docking network. Other assumptions are as follows:

- Every supplier sends products directly to assembly plants or thorough a cross-dock.

- There are multiple cross-docks with limited capacity in the distribution network.

- There is no inventory kept at the cross-docks which means that the total quantity of products picked up from suppliers should be equal to total amount that is delivered to plants.

- The load to be sent from each supplier to each plant is known $\left(d_{j l}\right)$. If $d_{j l}$ is more than vehicle capacity or near FTL, the solution is trivial and the vehicle is needed to go directly for that flow (from supplier $l$ to plant $j$ ) since consolidation is not possible in such a situation due to full truckload and it is more economical to go directly to destination.

- All vehicles have the same capacity and fleet of vehicles is homogeneous. The total load shipped by each vehicle cannot exceed the capacity.

\section{B. Mathematical Model}

The sets, parameters and variables used in the model are as follows:

Sets

$J \quad$ The set of assembly plants $\{j=1,2, \ldots, J\}$

$I \quad$ The set of cross-docks $\{i=1,2, \ldots, I\}$

$L \quad$ The set of suppliers $\{l=1,2, \ldots, L\}$

$K \quad$ The set of vehicles $\{k=1,2, \ldots, K\}$

\section{Parameters}

$c_{i j} \quad$ The transportation cost from node $i$ to node $j(i, j \in(L \cup I \cup J))$

$g_{i} \quad$ The fixed cost of establishing cross-dock $i$

$v_{i} \quad$ The variable cost per part unit at cross-dock $i$

$V_{i} \quad$ The maximum capacity of cross-dock $i$

$d_{j l} \quad$ Demand of plant $j$ from supplier $l$

$Q \quad$ The capacity of vehicles

\section{Decision variables}

$\mathrm{U}_{\mathrm{lj}}$ 1: if load from supplier $l$ to plant $j$ is sent directly; 0 : otherwise

$y_{i} \quad 1$ : if cross-dock $i$ is open; 0: otherwise

$Z_{i l}$ 1: if load from supplier $l$ is served by cross-dock $i$; 0 : otherwise

$F_{i j} \quad 1$ : if plant $j$ is served by cross-dock $i$; 0 : otherwise

$m_{l i} \quad$ The number of vehicles from supplier $l$ to cross-dock $i$ (nonnegative integer variable) 
$n_{i j} \quad$ The number of vehicles from cross-dock $i$ to plant $j$ (nonnegative integer variable)

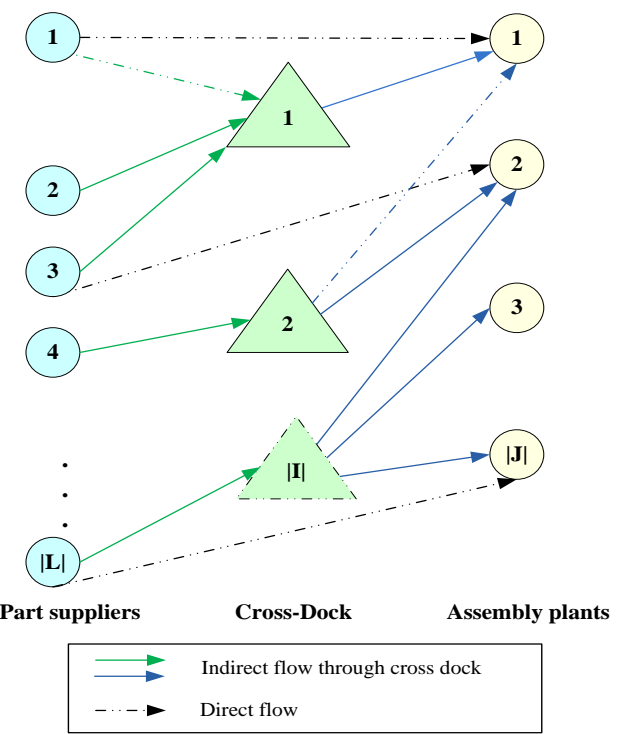

Fig. 1. Considered cross-docking network when direct flow is allowed

$R_{l i j} \quad$ 1: if demand of plant $j$ from supplier $l$ goes thorough crossdock $i$; 0: otherwise

$w_{i j} \quad$ Quantity of parts shipped from cross-dock $i$ to plant $j$.

With the notations introduced above, the problem can be formulated as a mathematical model as follows:

$$
\begin{gathered}
\operatorname{Min} \sum_{i \in I} g_{i} \times y_{i}+\sum_{j \in J} \sum_{l \in L} c_{l j} \times U_{l j}+\sum_{i \in I} \sum_{l \in L} c_{l i} \times m_{l i}+ \\
\sum_{i \in I} \sum_{l \in L} v_{i} \times\left\{\sum_{j \in J} d_{j l}\left(1-U_{l j}\right)\right\} \times Z_{i l}+\sum_{i \in I} \sum_{j \in J} c_{i j} \times n_{i j} \\
U_{l j}+\sum_{i \in I} R_{l i j}=\min \left\{1, d_{j l}\right\} ; \forall l, j \\
\sum_{j \in J} R_{l i j} \times d_{j l} \leq m_{l i} \times Q ; \forall i, l \\
\sum_{l \in L} d_{j l}\left(1-U_{l j}\right) \times Z_{i l}-F_{i j} \times w_{i j}=0 ; \forall i, j \\
\sum_{j \in J} w_{i j} \leq y_{i} \times V_{i} ; \forall i \\
Z_{i l} \leq \sum_{j \in I} R_{l i j} ; \forall l, i \\
\sum_{j \in I} R_{l i j} \leq|J| \times Z_{i l} ; \forall l, i \\
F_{i j} \leq \sum_{l \in L} R_{l i j} ; \forall i, j \\
\sum_{l \in L} R_{l i j} \leq|L| \times F_{i j} ; \forall i, j \\
w_{i j} \leq n_{i j} \times Q ; \forall i, j \\
y_{i}, U_{l j}, R_{l i j}, Z_{i l}, F_{i j} \in\{0,1\} \\
w_{i j} \geq 0 ;(i \in I ; j \in J) \\
m_{l i}, n_{i j} \in\{0,1,2, \ldots\}
\end{gathered}
$$

The objective function tries to minimize the total cost including fixed cost of establishing cross-dock, direct transshipment cost, indirect transportation cost from suppliers to cross-docks, variable cross-docking cost at receiving process and finally delivery cost to assembly plants. Constraint (2) ensures that each customer's demand is supplied via cross-docks or direct transshipment. Constraint (3) stipulates the maximum vehicle capacity. Equation (4) determines the load to be sent from cross-docks to assembly plants and also ensures that a flow entering a cross-dock is equal to the flow exiting it. Constraint (5) limits the flow through a cross-dock to its capacity.

Constraints (6) and (7) ensure that when $\Sigma \mathrm{j} R_{l i j}$ is positive, then $Z_{i l}$ should be equal to one, otherwise $Z_{i l}=0$. These constraints stipulate that cross-dock $\mathrm{i}$ gives service to supplier 1, if $R_{l i j}$ is equal to one, at least for one assembly plant. Constraints (8) and (9) are similar to (6) and (7), but in delivery process. Equation (10) determines the number of vehicles shipped from each cross-dock to each plant. The types of decision variables are defined in (11)-(13).

\section{EXPERIMENTAL STUDY}

In this section, the tractability of the proposed programming model is evaluated in terms of objective function value and required computational time. To do so, we perform some numerical experiments on a set of randomly generated problem instances in small and medium sizes. The programming model was implemented in GAMS 23.9 modeling language. All experiments were performed on a laptop with a Core 5 Duo CPU processor and 2 GB of RAM.

The problem sets are assumed to be as follows:

Set 1(10 3 2): 10 part suppliers, 3 cross-docks and 2 plants,

Set 2(15 3 3): 10 part suppliers, 3 cross-docks and 3 plants,

Set 3(15 5 3): 15 part suppliers, 5 cross-docks and 3 plants,

Set 4(15 5 4): 15 part suppliers, 5 cross-docks and 4 plants.

The maximum capacity of vehicles is assumed to be 100 . The demand of plants from suppliers is randomly generated in Uniform (10 and 90). Maximum capacity of cross-docks is set to 900 for set 1,2 and 3 and to 1500 for set 4 . Other values of data are presented in Table I.

\section{A. A Sample Instance}

For problem instance 1-1, the distribution of suppliers, cross-docks and plants are illustrated in Fig. 2. The vehicle capacity is 100 and variable cost at each cross-dock is set to 0.01. The written numbers under each supplier node indicates the demand of assembly plants from that supplier as is shown in Fig. 2.

For this instance, consider three possible scenarios: in the first one, all transshipments have to go directly from suppliers to plants and there is no cross-docking center in the network. In such a condition, totally 20 shipments (equivalent to 20 vehicles) are required to meet all the demand of two plants. For this scenario, cost terms of objective function are summarized in Table 2.

In the second scenario, it is assumed that all shipments have to pass through cross-docks and no direct shipment is allowed. In this condition, transportation costs from suppliers to plants $\left(c_{l j}\right)$, direct costs of transporting parts, are set to an extremely large number, thus all shipment are 
forced to pass through cross-docks. Cost terms of objective function in this scenario are summarized in Table III.

TABLE I: THE CHARACTERISTIC AND INTERVALS OF INSTANCES

\begin{tabular}{lc}
\hline \hline \multicolumn{1}{c}{ Parameters } & Intervals \\
\hline Transportation cost between each couple of nodes $\left(c_{i j}\right)$ & $\mathrm{U}(10,100)$ \\
Fixed cost of establishing cross-docks $\left(g_{i}\right)$ & $\mathrm{U}(200,500)$ \\
Variable cost per commodity unit at cross-dock $i\left(\mathrm{v}_{\mathrm{i}}\right)$ & $\mathrm{U}(0.01,1)$ \\
\hline \hline
\end{tabular}

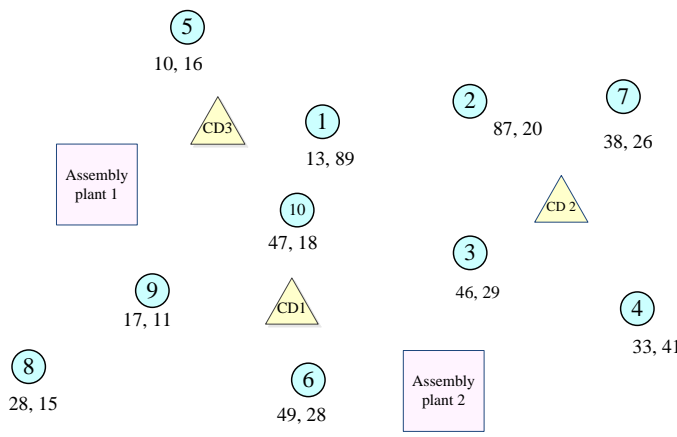

Fig. 2. The distribution of nodes in the simple instance.

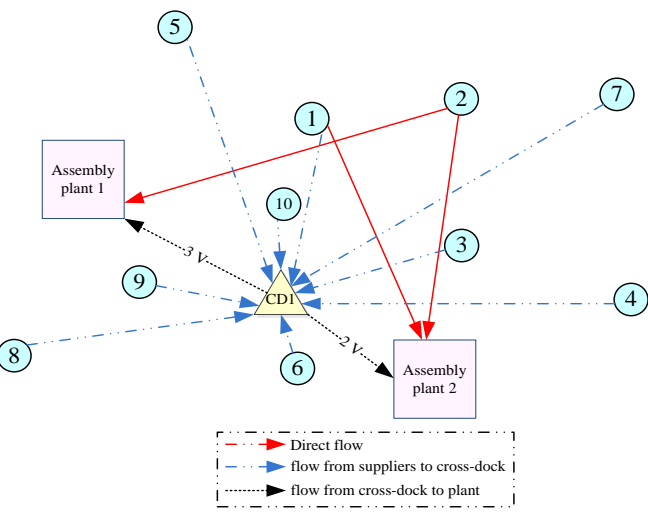

Fig. 3. The optimal solution of instance 1-1 solved by GAMS

In the third scenario, the optimal solution is found by GAMS software, when both transportation strategies are allowed. In this condition, the objective value of problem instance is 918.73 , which is $17.99 \%$ and $3.92 \%$ better than cost of scenario 1 and scenario 2, respectively. The cost terms of optimum problem are summarized in Table 4.

The optimal solution has been found by GAMS after 1387 seconds. In this solution cross-dock 1 is opened. Totally 591 commodity units pass this cross-dock, therefore if the model determines the best capacity of this cross-dock, it will be 591 units. Fig. 3 shows the optimal solution for this instance.

This simple instance shows that when more than one transportation strategy is utilized, the distribution cost of network may decrease. There are also conditions in which considering different transportation strategies does not necessarily have effect on cost.

TABLE II: COST TERMS OF OBJECTIVE FunCTION FOR PROBLEM INSTANCE

\begin{tabular}{lc}
\multicolumn{1}{c}{ Cost type } & Value \\
\hline \hline Fixed cost of establishing cross-dock & 0 \\
Direct transshipment cost & 1084 \\
Indirect transportation cost from suppliers to CDs (pick up cost) & 0 \\
Variable cross-docking cost at receiving process & 0 \\
Indirect transportation cost from CDs to plants (delivery cost) & 0 \\
Total cost & 1084 \\
\hline \hline
\end{tabular}

TABLE III: COST TERMS OF OBJECTIVE FUNCTION FOR PROBLEM INSTANCE 1-1 (SECOND SCENARIO)

\begin{tabular}{lc}
\hline \hline \multicolumn{1}{c}{ Cost type } & Value \\
\hline Fixed cost of establishing cross-dock & 200 \\
Direct transshipment cost & 0 \\
Indirect transportation cost from suppliers to CD (pick up cost) & 485 \\
Variable cross-docking cost at receiving process & 12.78 \\
Indirect transportation cost from CDs to plants (delivery cost) & 257 \\
Total cost & 954.78 \\
\hline \hline
\end{tabular}

TABLE IV: COST TERMS OF OBJECTIVE FunCTION FOR PROBLEM INSTANCE 1-1 (THIRD SCENARIO)

\begin{tabular}{lc}
\hline \hline \multicolumn{1}{c}{ Cost type } & Value \\
Fixed cost of establishing cross-dock & 200 \\
Direct transshipment cost & 172 \\
Indirect transportation cost from suppliers to CDs (pick up cost) & 353 \\
Variable cross-docking cost at receiving process & 8.73 \\
Indirect transportation cost from CDs to plants (delivery cost) & 185 \\
Total cost & 918.73 \\
\hline \hline
\end{tabular}

\section{B. Experimental Result}

Table V-VIII summarize the results for 20 problem instances. For each instance, it reports the total cost of distribution parts and computational time of executing. S shows the optimum number of opened cross-docks. It is clear that the computational time increases by increasing the number of suppliers and plants. The results are presented for problems with up to 15 suppliers.

TABLE V: COMPUTATIONAL RESUlTS FOR PROBLEM SET 1

\begin{tabular}{ccccccc}
\hline \hline \multirow{2}{*}{$\begin{array}{c}\text { Problem } \\
\text { instance }\end{array}$} & $\mathbf{L}$ & $\mathbf{I}$ & $\mathbf{J}$ & $\mathbf{S}$ & \begin{tabular}{c} 
Gbjective \\
\cline { 5 - 7 } value
\end{tabular} & $\begin{array}{c}\text { CPU } \\
\text { (sec) }\end{array}$ \\
\hline $1-1$ & 10 & 3 & 2 & 1 & 918.73 & 1387 \\
$1-2$ & 10 & 3 & 2 & 1 & 930.7 & 605 \\
$1-3$ & 10 & 3 & 2 & 1 & 1072.2 & 591 \\
$1-4$ & 10 & 3 & 2 & 1 & 905.6 & 1542 \\
$1-5$ & 10 & 3 & 2 & 1 & 1001.4 & 964 \\
\hline \hline
\end{tabular}

TABLE VI: COMPUTATIONAL RESULTS FOR PROBLEM SET 2

\begin{tabular}{ccccccc}
\hline \hline \multirow{2}{*}{$\begin{array}{c}\text { Problem } \\
\text { instance }\end{array}$} & $\mathbf{L}$ & $\mathbf{I}$ & $\mathbf{J}$ & $\mathbf{S}$ & \begin{tabular}{c} 
Gbjective \\
\cline { 5 - 7 } value
\end{tabular} & $\begin{array}{c}\text { CPU } \\
\text { (sec) }\end{array}$ \\
\hline $2-1$ & 15 & 3 & 2 & 3 & 1489.1 & 883 \\
$2-2$ & 15 & 3 & 2 & 2 & 1180.6 & 802 \\
$2-3$ & 15 & 3 & 2 & 2 & 1077.6 & 945 \\
$2-4$ & 15 & 3 & 2 & 2 & 1235.4 & 1338 \\
$2-5$ & 15 & 3 & 2 & 2 & 1334.7 & 1049 \\
\hline \hline
\end{tabular}

TABLE VII: COMPUTATIONAL RESULTS FOR PROBLEM SET 3

\begin{tabular}{ccccccc}
\hline \hline \multirow{2}{*}{$\begin{array}{c}\text { Problem } \\
\text { instance }\end{array}$} & $\mathbf{L}$ & $\mathbf{I}$ & $\mathbf{J}$ & $\mathbf{S}$ & $\begin{array}{c}\text { Gbjective } \\
\text { value }\end{array}$ & $\begin{array}{c}\text { CPU } \\
\text { (sec) }\end{array}$ \\
\hline $3-1$ & 15 & 5 & 2 & 2 & 1172.3 & 1002 \\
$3-2$ & 15 & 5 & 2 & 3 & 1229.9 & 836 \\
$3-3$ & 15 & 5 & 2 & 2 & 1045.6 & 1102 \\
$3-4$ & 15 & 5 & 2 & 2 & 1135.1 & 1535 \\
$3-5$ & 15 & 5 & 2 & 2 & 1079.3 & 1113 \\
\hline \hline
\end{tabular}

TABLE VIII: COMPUTATIONAL RESULTS FOR PROBLEM SET 4

\begin{tabular}{cccccccc}
\hline \hline \multirow{2}{*}{$\begin{array}{c}\text { Problem } \\
\text { instance }\end{array}$} & $\mathbf{L}$ & $\mathbf{I}$ & $\mathbf{J}$ & & \multicolumn{3}{c}{ GAMS } \\
\cline { 5 - 7 } & & & & & $\mathbf{S}$ & $\begin{array}{c}\text { Objective } \\
\text { value }\end{array}$ & $\begin{array}{c}\text { CPU } \\
\text { (sec) }\end{array}$ \\
\hline $4-1$ & 15 & 5 & 4 & 3 & 3505.4 & 2426 \\
$4-2$ & 15 & 5 & 4 & 3 & 3664.9 & 2075 \\
$4-3$ & 15 & 5 & 4 & 3 & 3290.3 & 2527 \\
$4-4$ & 15 & 5 & 4 & 3 & 3134.0 & 2882
\end{tabular}




$\begin{array}{lllllll}4-5 & 15 & 5 & 4 & 2 & 2986.2 & 3239\end{array}$

\section{CONCLUSION}

This paper addresses the transportation and location problem of cross-docking network where the shipments are allowed to be transferred from suppliers to plants directly as well as via cross-docking approach. Cross-docking is a logistics strategy with the aim of reducing inventory and transportation costs, order picking and delivery time of demands in the supply networks. This strategy simply deals with supplying demand of multiple final destinations from various origins by consolidating shipments. The objective function tries to find the best location of cross-docks and distribution plan such that the total transportation cost is minimized. In order to solve the proposed model, totally 20 instances are defined in four problem sets and solved by GAMS software. The results are reported for each problem instance in term of objective function value and computational time.

As some directions for future studies, a heuristic algorithm can be used to solve large sized problems. In addition, time windows can be considered at supplier and plant locations in order to minimize transportation time. Moreover, the capacity of cross-dock can be optimized by the model instead of being a constraint.

\section{REFERENCES}

[1] U. M. Apte and S. Viswanathan, "Effective cross docking for improving distribution efficiencies," International Journal of Logistics, vol. 3, pp. 91-302, 2000

[2] S. C. Chopra and P. Meindl, Supplier Chain Management - Strategies, Planning, and Operation, Prentice Hall, Upper Saddle River, New Jersey. pp. 22-23, 2001.

[3] D. Vasiljevic, M. Stepanovic, and O. Manojlovic, "Cross docking implementation in distribution of food products," Economics of Agriculture, vol. 60, pp. 91-101, 2013.

[4] A. Ross and V. Jayaraman, "An evaluation of new heuristics for the location of cross-docks distribution centers in supply chain network design," Computers and Industrial Engineering, vol. 55, pp. 64-79, 2008.

[5] Y. H. Lee, J. W. Jung, and K. M. Lee, "Vehicle routing scheduling for cross-docking in the supply chain," Computers and Industrial Engineering, vol. 51, pp. 247-256, 2006

[6] C. J. Liao, Y. Lin, and S. C. Shih, "Vehicle routing with crossdocking in the supply chain," Expert Systems with Applications, vol. 37, pp. 6868-6873, 2010.

[7] B. Vahdani, R. Tavakkoli-Moghaddam, M. Zandieh, and J. Razmi, "Vehicle routing scheduling using an enhanced hybrid optimization approach," Journal of Intelligent Manufacturing, vol. 23, pp. 759-774, 2012.

[8] R. Musa, J. P. Arnaout, and H. Jung, "Ant colony optimization algorithm to solve for the transportation problem of cross-docking network," Computers and Industrial Engineering, vol. 59, pp. 85-92, 2010.

[9] R. Dondo, C. A. Méndez, and J. Cerdá, "The multi-echelon vehicle routing problem with cross docking in supply chain management," Computers and Chemical Engineering, vol. 35, pp. 3002-3024, 2011.

[10] H. Ma, Z. Miao, A. Lim, and B. Rodrigues, "Cross docking distribution networks with setup cost and time window constraint," Omega, vol. 39, pp. 64-72, 2011.
[11] F. A. Santos, G. R. Mateus, and A. S. da Cunha, "The pickup and delivery problem with cross-docking," Computers and Operations Research, vol. 40, pp. 1085-1093, 2013.

[12] F. A. Santos, G. R. Mateus, and A. S. da Cunha, "A branch-and-price algorithm for a vehicle routing problem with cross docking," Electronic Notes in Discrete Mathematics, vol. 37, pp. 249-254, 2011.

[13] D. Konur and M. M. Golias, "Cost-stable truck scheduling at a crossdock facility with unknown truck arrivals: A meta-heuristic approach," Transportation Research Part E, vol. 49, pp. 71-91, 2013

[14] C. D. Tarantilis, "Adaptive multi-restart tabu search algorithm for the vehicle routing problem with cross-docking," Optim Lett, vol. 7, pp. $1583-1596,2013$.

[15] S. M. Mousavi and R. Tavakkoli-Moghaddam, "A hybrid simulated annealing algorithm for location and routing scheduling problems with cross-docking in the supply chain," Journal of Manufacturing Systems, vol. 32, pp. 335-347, 2013.

[16] S. M. Mousavi, B. Vahdani, R. Tavakkoli-Moghaddam, and H. Hashemi, "Location of cross-docking centers and vehicle routing scheduling under uncertainty: A fuzzy possibilistic-stochastic programming model," Applied Mathematical Modelling, vol. 38, pp. 2249-2264, 2014.

[17] A. H. Goodarzi and S. H. Zegordi, "A location- routing problem for cross-docking networks: a biogeography-based optimization algorithm," Computers and Industrial Engineering, vol. 102, pp. 132146, 2016.

[18] D. Agustina, C. K. M. Lee, and R. Piplani, "A review: Mathematical models for cross docking planning," International Journal of Engineering Business Management, vol. 2, pp. 47-54, 2010.

[19] J. Van Belle, P. Valckenaers, and D. Cattrysse, "Cross-docking: State of the art," Omega, vol. 40, pp. 827-846, 2012.

[20] P. Buijs, I. F. A. Vis, and H. J. Carlo, "Synchronization in crossdocking networks: A research classification and framework," European Journal of Operational Research, vol. 239, pp. 593-60, 2014.

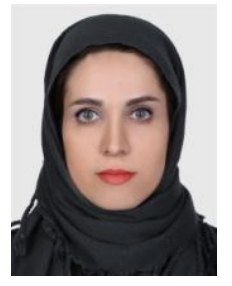

A. Hasani Goodarzi is a $\mathrm{PhD}$ candidate on Industrial Engineering in the faculty of Industrial \& Systems Engineering at Tarbiat Modares University, Tehran, Iran. She recently was a visitor at Grenoble INP University, Grenoble, France and passed a sabbatical in G-SCOP laboratory. She received her Msc from Department of Industrial Engineering at University of Tehran, Iran in 2013. She holds a BSc in Industrial Engineering from Isfahan University of Technology, Iran.

Her main areas of research interests include supply chain management, operation research, multi-objective optimization, and combinatorial optimization. She has published articles in international conferences and academic journals including Computers and Industrial Engineering and Applied Mathematical Modeling.

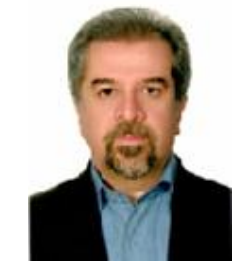

S. H. Zegordi is an associate professor of industrial engineering in the School of Engineering at Tarbiat Modares University, Iran. He received his $\mathrm{PhD}$ from Department of Industrial Engineering and management at Tokyo Institute of Technology, Japan in 1994. He holds an MSc in industrial engineering and systems from Sharif University of Technology, Iran and a BSc in industrial engineering from Isfahan University of Technology, Iran. His main areas of teaching and research interests include production planning and scheduling, multi-objective optimization problems, meta-heuristics, quality management and productivity. He has published several articles in international conferences and academic journals including European Journal of Operational Research, International Journal of Production Research, Journal of Operational Research Society of Japan, Computers \& Industrial Engineering and Amirkabir Journal of Science and Engineering. 